San Jose State University

SJSU ScholarWorks

Faculty Publications

Economics

7-1-2006

\title{
Incorporating Policymaker Costs and Political Competition into Rent-Seeking Games
}

\author{
R. Kenneth Godwin \\ University of North Carolina
}

Edward J. Lopez

San Jose State University, edwardjlopez@gmail.com

Barry J. Seldon

University of Texas at Dallas

Follow this and additional works at: https://scholarworks.sjsu.edu/econ_pub

Part of the Political Economy Commons, and the Public Economics Commons

\section{Recommended Citation}

R. Kenneth Godwin, Edward J. Lopez, and Barry J. Seldon. "Incorporating Policymaker Costs and Political Competition into Rent-Seeking Games" Southern Economic Journal (2006): 37-54.

This Article is brought to you for free and open access by the Economics at SJSU ScholarWorks. It has been accepted for inclusion in Faculty Publications by an authorized administrator of SJSU ScholarWorks. For more information, please contact scholarworks@sjsu.edu. 


\author{
R. Kenneth Godwin, ${ }^{*}$ Edward J. López, † and Barry J. Seldon+
}

\begin{abstract}
We incorporate policymaker costs of supplying rents and variable intensities of competition among rent seekers into the standard rent-seeking game. By incorporating these aspects, the game has greater verisimilitude to the lobbying process. The first aspect captures the fact that in rent-seeking contests there is a positive probability that neither firm will obtain the rent. The second aspect captures the fact that firms seeking different rents still must compete for policymakers' resources. We find that lobbying expenditures, rent-seeking profits, and rent dissipation depend on the intensity of competition and the value of the rent relative to policymaker costs. For example, if the value of the rent is sufficiently high relative to policymakers' costs, an increase in the intensity of political competition will increase lobbying expenditures; otherwise, expenditures fall as competitive intensity increases. In addition, the model establishes pure-strategy equilibria with underdissipation where only mixedstrategy equilibria exist in the standard model.
\end{abstract}

JEL Classification: D72, H42, L51

\title{
1. Introduction
}

Rent seeking in politics involves agents who lobby policymakers for potential benefits. In a seminal contribution, Tullock (1980) modeled rent seeking as a lottery game. A major weakness of Tullock's game was that it lacked verisimilitude to actual rent seeking because it omitted politics. The absence of politics meant that the game essentially assumed that there are no costs to the policymakers of supplying rents. But as Tollison (1997) and others have pointed out, these costs are not zero, and the politics surrounding the policy decision influence the pattern of lobbying and the rent-seeking outcome. In this paper we address two aspects of those politics: the costs to policymakers of supplying rents and the variable intensity of political competition among a given number of rent seekers. Including these aspects increases the similarity of the game to actual rent-seeking situations and makes clearer the incentives to rent seekers.

* Department of Political Science, 400 Fretwell Hall, University of North Carolina, 9201 University City Boulevard, Charlotte, NC 28223-0001, USA; E-mail godwink@email.uncc.edu.

+ Department of Economics, 147 Dudley Moorhead Hall, San José State University, One Washington Square, San José, CA 95192-0114, USA: E-mail edward.lopez@sjsu.edu.

$\ddagger$ Economics Program. School of Social Sciences-GR 31, The University of Texas at Dallas, 2601 N. Floyd Road, Richardson, TX 75080, USA; E-mail seldon@utdallas.edu; corresponding author.

Authors' names appear in alphabetical order. For helpful comments and suggestions, the authors thank David AustenSmith, Jeffrey Banks, Catherine Eckel. Alan Lockard, Mike Munger, Joanna Robinson, Robert Tollison, Gordon Tullock, two anonymous referees, and participants at meetings of the Western Economic Association, the Public Choice Society, and the Southern Economic Association. The authors also thank Shilpi Bihari, John Hereford, and Ozge Ozden for research assistance. Support for this research was provided by the Earhart Foundation and the Center for Study of Public Choice.

Received May 2004; accepted September 2005. 
Costs to supplying rents arise due to various constraints. Legislators must build coalitions, acquire parliamentary rights, maintain a positive image, and service constituent interests. Policymakers in agencies must follow procedural rules, submit to congressional oversight and budgeting, pass OMB reviews, and so forth. Lower policymaker costs should increase the effectiveness of lobbying, and this should attract greater lobbying efforts among rent seekers. ${ }^{1}$ Increasing policymaker costs makes lobbying less effective. Indeed, because of these costs policymakers often turn away lobbies emptyhanded. In short, policymakers have constraints that affect the policies they design, and this affects lobbying expenditures (Dougan and Snyder 1993). This paper introduces policymaker costs in monetary units, such that they are comparable to the value of the rent and rent-seeking expenditures.

Political competition among rent seekers also influences the rent-seeking outcome. Competition traditionally has been modeled by varying the number of rent-seeking agents (actual or potential) or their relative lobbying expenditures (e.g., Posner 1975; Rogerson 1982; Sun and Ng 1999). Competition can vary, however, even among a given number of rent seekers and for a given profile of expenditures. For example, two agents may lobby a policymaker for the same unique and exclusive political good. Then one agent directly opposes the other and only one agent can win the good. Alternatively, the same two agents may lobby a policymaker for two separate political goods. In that case, the agents oppose each other only indirectly. This situation is frequent in politics as rent-seeking agents compete for space on the political agenda, for policymakers' time, and for portions of a particular government budget. In this situation, success by one agent does not necessarily result in failure by the other, but it does lower the probability that the other agent will succeed. Competition is more intense in the first example, even though the examples involve the same number of firms. Industrial organization economists have shown that a single parameter can determine incumbent firms' competition in price and quantity regardless of the number of firms present. ${ }^{2}$ This paper introduces rent-seeking competition analogously, allowing a parameter to alter the competitiveness of the rent-seeking game among a fixed number of firms.

We incorporate monetized policymaker costs and the political competition parameter into the success probabilities of the standard rent-seeking game. The resulting model is a game in which the agents' simultaneous maximization of expected net retums (or profits) determines a Nash equilibrium in their expenditures. Incorporating politics into the standard game makes the game more accurate because equilibrium and comparative statics depend in part on the politics of the rent-seeking contest. More specifically, increasing political competition decreases rent-seeking expenditures unless the value of the rent is sufficiently large relative to policymaker costs; and dissipation rates are lower than in previous research because of policymaker costs. Furthermore, under increasing returns to expenditures there is a unique pure-strategy equilibrium with underdissipation of rents, unlike the standard game, which has stochastic mixed-strategy equilibria with overdissipation occurring about half the time.

Intuitively, in the model incorporating politics, rent seekers will avoid competition with each other, search for low-cost providers of political goods, and generally avoid overdissipation. With such implications, our model extends the Tullock game in a political-economic sense, reaching more empirically reasonable results than previous models.

\footnotetext{
' Organized interests concentrate campaign contributions on legislators with greater partiamentary power over their issue set (Grier and Munger 1991; Kroszner and Stratmann 1998).

2 The magnitude of a single variable, the conjectural variation, deternines whether two finns act as if they are competitive fims, pricing at marginal cost, or if they act as a cartel, maximizing their profits as would a multiplant monopolist (see Waterson 1984 for a concise discussion).
}

\section{The Stan \\ Followin $R_{1}$ and $R_{2}$ anc}

where $P_{1}+i$ expenditures; proportionate game is "unbi $n=2$ in an unl Following cor for $n$ agents), of the rent, an basis of Tullo

Many ga models that fo with increasin. seekers, budg! a consequenct policymaker c seeking takes 1 observed (Tol]

\section{Rent Seel}

In previo to their relativs (e.g., Baye, $\mathrm{K}$ a lottery; and $i$ player $i$ 's suc according to $p$ assumes a cos policymaker $\mathrm{o}$. number of inst middle-level $\pi$ oversight, and major legislati

\footnotetext{
${ }^{3}$ We refer to the $c$ do not intend to $i$ 1971; Peltzman list here (Tolliso ${ }^{4} \sigma$ does not indic ${ }^{5}$ For a compilatio
} 
iild coalitions, acquire ests. Policymakers in udgeting, pass OMB ; of lobbying, and this ymaker costs makes away lobbies emptysign, and this affects oolicymaker costs in seeking expenditures. utcome. Competition actual or potential) or and Ng 1999). Comfor a given profile of unique and exclusive t can win the good. olitical goods. In that olitics as rent-seeking nd for portions of a necessarily result in ucceed. Competition me number of firms. determine incumbent present. ${ }^{2}$ This paper the competitiveness

n parameter into the a game in which the $s$ a Nash equilibrium game more accurate rent-seeking contest. enditures unless the rates are lower than creasing returns to of rents, unlike the ion occurring about

mpetition with each ssipation. With such nse, reaching more

ower over their issue set ey are competitive firms, olist (see Waterson 1984

\section{The Standard Rent-Seeking $\mathrm{Model}^{3}$}

Following Tullock (1980), consider two agents competing for a private good with expenditures $R_{1}$ and $R_{2}$ and success probabilities

$$
P_{1}=\frac{R_{1}^{\sigma}}{R_{1}^{\sigma}+R_{2}^{\sigma}} \quad \text { and } \quad P_{2}=\frac{R_{2}^{\pi}}{R_{1}^{\sigma}+R_{2}^{\sigma}},
$$

where $P_{1}+P_{2}=1$, which implies that one agent must win. $\sigma$ indicates "returns to scale" in expenditures; for example, if $\sigma>1$, then an increase in $R_{i}$, ceteris paribus, causes a more than proportionate increase in agent $i$ 's probability of winning. ${ }^{4}$ If $\sigma$ is the same for both agents, then the game is "unbiased": the agents are equally suited to rent seeking. Tullock reasoned that if $\sigma=2$ and $n=2$ in an unbiased game, then combined symmetric expenditures would equal the value of the prize. Following convention, we call this "exact dissipation." But if $\sigma>2$ for two agents (or $\sigma>n /(n-1)$ for $n$ agents), Tullock reasoned that total spending in an unbiased game will always exceed the value of the rent, and this usually will occur in biased games. This result is "overdissipation" and forms the basis of Tullock's social waste argument.

Many game theorists were attracted to Tullock's curious result, and most of the rent-seeking models that followed attempted to rule out overdissipation in equilibrium. New contributions emerged with increasing complexities, such as open-ended sequential games, uncertain prizes, risk-averse rent seekers, budget constraints, entry conditions, and various sharing rules for groups of winners. As a consequence, this literature formalized and generalized Tullock's reasoning. ${ }^{5}$ By incorporating policymaker costs and political competition into the basic model, this paper formalizes the idea that rent seeking takes place within a political context that influences patterns of rent seeking and the outcomes observed (Tollison 1997). The model suggests a more politically realistic solution to overdissipation.

\section{Rent Seeking with Policymaker Costs and Political Competition}

In previous formulations of rent-seeking contests, players' success probabilities are related only . to their relative lobbying expenditures, regardless of the value of $\sigma$. It has been noted in several places (e.g., Baye, Kovenock, and de Vries 1994; Che and Gale 1997) that if $\sigma$ is finite, then the game is a lottery; and if $\sigma \rightarrow \infty$, then the game is an all-pay auction. For any finite value of $\sigma$, the chances of player $i$ 's success increase directly with expenditures $R_{i}$. In the lottery, the winner is selected according to probabilities; in the all-pay auction the winner is the highest bidder. Such an approach assumes a costless political process. In contrast, define $N \in(0, \infty)$ as the monetized disutility to the policymaker of providing the rent. Thus conceived, the policymakers' costs may be influenced by any number of institutional factors. For instance, $N$ may depend on the political body that is lobbied. For middle-level regulatory waivers, there may be a small number of policymakers involved, little formal oversight, and negligible lobbying opposition - in this case $N$ may be close to zero. Alternatively, for major legislative changes in which a winning coalition must form against powerful opposition and

\footnotetext{
${ }^{3}$ We refer to the class of games that follow the approach based on Tullock's (1980) lottery game as the "standard model." We do not intend to implicate other branches of the literature that have incorporated politics such as the theory of regulation (Stigler 1971; Peltzman 1976; McCormick and Tollison 1981; Becker 1983) or various empirical approaches that are too numerous to list here (Tollison 1997 provides an up-to-date survey).

${ }^{4} \sigma$ does not indicate returns to scale as usually defined, but we maintain this terminology of the literature.

${ }^{5}$ For a compilation of this literature, see Lockard and Tullock (2001).
} 
re-election constraints, $N$ may be very high. Policymaker costs also could depend on the selection of a voting rule-majority rule would have a lower $N$ than would a supermajority rule. Stronger checks and balances also affect policymaker costs: for U.S. style judicial review, $N$ may be moderate, but for Swiss style legislative referendum, $N$ may be much higher (Moser 2000; Spindler and de Vanssay 2003). Individual policymakers can have different values of $N$, depending on their regulatory/ parliamentary power over a policy (Denzau and Munger 1986; Grier and Munger 1991). Public perception may help to determine $N$ if it involves a policy that would attract substantial negative media attention to the policymaker(s).

Consider next the nature of competition among rent seekers. It may depend on the number of rent seekers and entry conditions, as demonstrated in many contributions to both the empirical and theoretical rent-seeking literature. However, political competition can also emerge among a given number of rent seekers. For example, two firms may compete for a single contract to produce tires for government vehicles. If only one firm can receive the contract, the success of a firm completely precludes the success of its rival. In this case, political competition is high. In contrast, suppose two defense contractors are lobbying to increase the price each receives for weapons sold to the government. If one firm's success in obtaining a price increase has little impact on the probability that the other firm will also obtain an increase, then political competition is low. If, however, policymakers face a tight budget constraint, then one firm's success can significantly affect the other firm's probability of obtaining its objective, and the competition between them is higher. Nevertheless, competition would be less than between firms bidding for the same rent if only one can succeed. To introduce this concept of political competition into the model, we define $\alpha \in(0,1]$ as an index of competition that increases with the degree of competition in the contest.

For the moment, suppose that there are two players, Firm 1 and Firm 2, which incur expenditures $R_{1}$ and $R_{2}$ in lobbying to acquire a rent of value $V$ to each firm, and that $\sigma=1{ }^{6}$ We express the probabilities of success or failure for Firm $i$, where $i=1,2$ and, in the following, $i \neq j$, as

$$
\begin{aligned}
P_{i} & =\frac{R_{i}}{R_{i}+\alpha R_{j}+N}=\text { probability that Firm } i \text { receives the good; } \\
1-P_{i} & =\frac{\alpha R_{j}+N}{R_{i}+\alpha R_{j}+N}=\text { probability that Firm } i \text { fails to receive the good, }
\end{aligned}
$$

where it is possible that neither firm will succeed, and where $\alpha$ represents the degree of competition between the rent seekers. If $\alpha<1$, there are four possible ex-post states of the world: (1) both firms may succeed in their lobbying; (2) both firms may fail; (3) Firm 1 may succeed and Firm 2 may fail; and (4) Firm 1 may fail and Firm 2 may succeed. The competition parameter $\alpha$ signifies the importance to Firm $i$ of Firm $j$ 's lobbying expenditures. The higher $\alpha$ is, the more Firm $j$ 's expenditure reduces Firm $i$ 's probability of success. At the upper bound, if $\alpha=1$ and Firm $i$ succeeds, then Firm $j$ will fail. Here there are three possible outcomes: (1) Firm 1 may win, in which case Firm 2 fails; (2) Firm 2 may win, so Firm 1 fails; and (3) both firms may fail. ${ }^{7}$ When $\alpha=1$, the expenditure of a firm that increases its probability of success has a very deleterious effect on the other firm's probability of winning. In contrast, if one firm's success does not preclude the other firm's success, $\alpha$ takes a value

\footnotetext{
${ }^{6}$ Different valuations of the rent to the two firms are plausible but would not change our main results. We discuss the implications of different valuations below. Similarly, we consider different values of $\sigma$ below.

${ }^{7}$ If $\alpha=1$, we have an extension of the standard game because, in that case, probability (2) is the sum of the probability that Firm $j$ receives the good, expressed as $R_{j} /\left(R_{i}+R_{j}+N\right)$, and the probability that neither firm receives the rent, expressed as $N /\left(R_{i}+R_{j}+\right.$ $N)$. Adding the probability that Firm $i$ receives the rent, expressed as $R_{i} /\left(R_{i}+R_{j}+N\right)$, we have three probabilities that sum to one. Alternatively, if $\alpha<1$, each firm has a prohability of success and a probability of failure. In this case, there are four probabilities.
}

less than 1. For low lower bound, if $\alpha=$ probability: becaus interested in rent-st

Obviously, Pn firm spends more. 7 than one; thus there a decrease in the pr neither wins. Finall

\section{The Model}

We model tw returns from lobbyi firm. For now, we a We also assume th: expected profits, th

where the expendit lobbying in expects case, where $\alpha \in(0$, different numbers $\mathrm{c}$ returns to marginal

The second derivat the value of $V$ were the following

AsSUMPTION 1

This will be suffici the rent.

Equation $4 \mathrm{im}$ ] $R_{i} \geq 0$ that satisfies

The proof that Eque Equation 5, so the I

\footnotetext{
${ }^{8}$ The second derivative
} 
$d$ on the selection of ule. Stronger checks be moderate, but for ller and de Vanssay on their regulatory/ unger 1991). Public substantial negative

Id on the number of th the empirical and erge among a given t to produce tires for f a firm completely In contrast. suppose Neapons sold to the n the probability that wever, policymakers ect the other firm's igher. Nevertheless, one can succeed. To $0,1]$ as an index of $\mathrm{h}$ incur expenditures 1. ${ }^{6}$ We express the ig, $i \neq j$, as

good

gree of competition 'orld: (1) both firms nd Firm 2 may fail; ter $x$ signifies the irm $j$ 's expenditure ucceeds, then Firm 1 case Firm 2 fails; spenditure of a firm rm's probability of ss, $x$ takes a value

esults. We discuss the e probability that Firn $j$ xpressed as $N /\left(R_{t}+R_{j}+\right.$ ibilities that sum to one. re are four probabilities. less than 1. For lower values of $\boldsymbol{x}$. the probability of Firm $i$ 's success is higher for any given $R_{j}$. At the lower bound, if $\alpha=0$, there is no effect at all of one firm's expenditures on the other firm's success probability: because $\alpha=0$ the rival's term disappears from the probability equations. Because we are interested in rent-seeking competition, however, we bound $\alpha$ away from 0 .

Obviously, Probabilities (1) and (2) sum to one and each firm's success probability increases as the firm spends more. These features carry over from the standard game. For any $N>0, P_{i}$ and $P_{j}$ are less than one; thus there is a positive probability that neither firm wins the rent. For an increase in $N$, there is a decrease in the probability of each firm's success and, therefore, an increase in the probability that neither wins. Finally, the standard game is a special case of our model, in which $\alpha=1$ and $N=0$.

\section{The Model}

We model two agents (viz., firms) in a simultaneous game. The firms maximize expected net returns from lobbying, which we refer to simply as "profits." Let $V>0$ be the value of the rent to the firm. For now, we assume these benefits to be equal for both firms so that their problems are identical. We also assume that the firms are equally adept at lobbying. Thus, for $i, j=1,2$ each firm maximizes expected profits, the difference between expected returns and the cost of lobbying, by

$$
\max _{R_{i}} \prod_{i}=\left[\frac{R_{i}}{R_{i}+\alpha R_{j}+N}\right] V-R_{i}
$$

where the expenditure terms are linear. We need only include the probability of the firm succeeding in lobbying in expected profits. Thus Equation 3 expresses the expected profit in the less competitive case, where $\alpha \in(0,1)$, as well as in the highly competitive case, where $\alpha=1$, so $\alpha \in(0,1]$, despite the different numbers of ex-post states of the world. The first-order condition equates marginal expected retums to marginal cost, so

$$
\frac{\partial \prod_{i}}{\partial R_{i}}=\left[\frac{\alpha R_{j}+N}{\left(R_{i}+\alpha R_{j}+N\right)^{2}}\right] V-1=0
$$

The second derivative is negative, so the solution to Equation 4 maximizes profits. ${ }^{8}$ Of course, if the value of $V$ were small enough relative to political $\operatorname{costs} N$, then firms would not lobby. We make the following

Assumption 1: $V>N$.

This will be sufficient to ensure that the firms have the incentive to make expenditures in seeking the rent.

Equation 4 implicitly yields the profit-maximizing level of $R_{i}$; and defining the set containing any $R_{i} \geq 0$ that satisfies profit maximization as the firm's best reply, $\rho_{i}$, results in the best reply function

$$
\rho_{i}=\left\{\begin{array}{cl}
\sqrt{\left(\alpha R_{j}+N\right) V}-x R_{j}-N & \text { for } 0 \leq R_{j} \leq \frac{(V-N)}{\alpha} \\
0 & \text { for } \frac{(V-N)}{x}<R_{j}
\end{array}\right.
$$

The proof that Equation 5 is the best reply function is in Appendix A. There, we show that $\Pi_{i} \geq 0$ on Equation 5, so the profit-maximizing firm does not incur an expected loss on the best reply function,

\footnotetext{
${ }^{8}$ The second derivative is $-\left\{2\left(x R_{j}+N\right) /\left[\left(R_{i}+x R_{j}+N\right)^{3}\right]\right\} V<0$ because $R_{j} \geq 0$ and $V, \alpha, N$ are all positive.
} 
and that the best reply function is strictly concave over $R_{j} \leq(V-N) / \alpha$, which is useful later in establishing equilibrium.

In Appendix B we show that the exact shape of Firm $i$ 's best reply function depends on the value of $V$ relative to $N$. For $V \leq 4 N$ (so the value of the rent is relatively small compared with policymakers' costs), $\rho_{i}$ is monotonically decreasing in $R_{j}$, and the firm would reduce lobbying expenditures as its rival's expenditures increase; in essence acquiescing to its rival because the rent is not worth the fight. But if $V>4 N$, then $\rho_{i}$ has an interior maximum at $R_{j}=(V / 4-N) / \alpha$, so if the rent is relatively valuable there is a range over lower levels of the rival's expenditures in which the firm's expenditures increase with that of its rival's. The firm is willing to challenge the rival to gain the relatively valuable rent. ${ }^{9}$

Because the shape of $\rho_{i}$ depends on the relative values of $V$ to $N$, equilibrium also depends on the relative values. In Appendix $\mathrm{C}$, we provide existence and uniqueness proofs for the equilibrium when $V \leq 4 N .{ }^{10}$ For all $V>4 N$, there likely exists a unique equilibrium, but we can only prove uniqueness for $4[(1+\alpha) / \alpha]^{2} N>V>4 N$. It is possible that three equilibria might exist if $V$ is even larger than $4[(1+\alpha) / \alpha]^{2} N$, but we have been unable to construct a numerical example of such a game, and we doubt that one exists. Examples of best reply functions and equilibria are shown in Figure 1, where Figure $1 \mathrm{~A}$ has $V<4 N$, Figure 1B has $4[(1+\alpha) / \alpha]^{2} N>V>4 N$, and Figure $1 \mathrm{C}$ has $V>4[(1+\alpha) /$ $\alpha]^{2} N>4 N$, with a unique equilibrium. Stability is indicated by the directional arrows in the figures. Figure ID shows the possibility of multiple equilibria, but the arrows indicate that the symmetrical equilibrium is the only stable equilibrium.

In Appendix D, we show that Firm $i$ 's lobbying expenditure in a symmetrical equilibrium is

$$
\rho_{e}=\frac{\sqrt{4(1+\alpha) N V+\alpha^{2} V^{2}}+\alpha V-2(1+\alpha) N}{2(1+\alpha)^{2}},
$$

where the $e$ subscript denotes equilibrium. By substituting Equation 6 into the profit Equation 3, we can express equilibrium firm profit as

$$
\prod_{i}^{e}=\left[\frac{\rho_{e}}{\rho_{e}+\alpha \rho_{e}+N}\right] V-\rho_{e}
$$

where $\rho_{e}=\rho_{e}(V, N, \alpha)$ for both firms.

\section{Comparative Statics}

We next consider the comparative statics of expenditures and profits with respect to competition. First, we show the effect of competition on equilibrium lobbying expenditures. In Appendix $E$ we prove

THEOREM 1: (1) If $V / 4 \leq N$, then $\partial \rho_{e} / \partial \alpha<0$ at all levels of $\alpha \in(0,1]$. (2) If $V / 4>N$, then $\partial \rho_{e} /$ $\partial \alpha$ is greater than, equal to, or less than 0 as $\alpha$ is less than, equal to, or greater than $(V-4 N) / V$ or, equivalently, as $(1-\alpha) V / 4$ is greater than, equal to, or less than $N$.

This suggests that if the value of the rent is sufficiently small relative to $N$, then equilibrium

\footnotetext{
9 These changes in the firm's expenditures are hypothetical, being based on its rival's action. The equilibrium is static, but the intuition concerning the shape of the reaction function seems reasonable and lends credence to the model.

${ }^{10}$ We cannot use the existence and uniqueness proofs from Esteban and Ray (1999), which depend on a thrice continuously differentiable, strictly concave cost function. In this section, cost is linear.
}

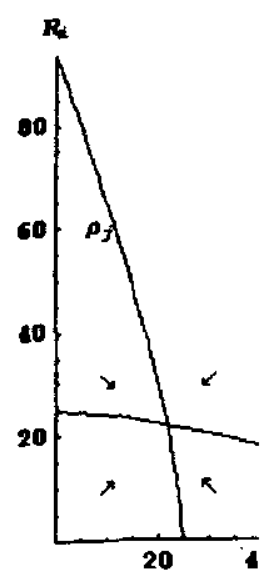

Figure 1A: ! where $V=10$

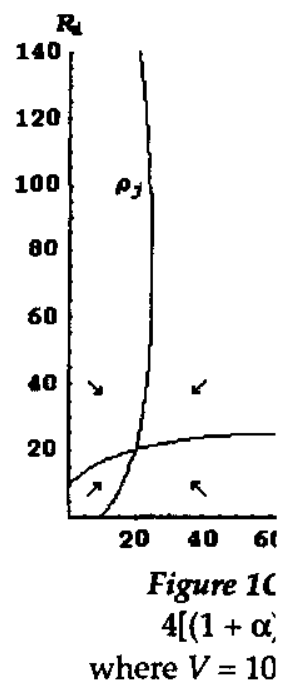

Figure 1. The shape o

lobbying expenditu then there is a rang competition increas and in Figure 1B, ( these figures, lobby Figure 1C, $(1-\alpha)$ equilibrium, the eq Intuitively, on expenditures. This entry conditions to however, predicts 
1 is useful later in

:pends on the value with policymakers' expenditures as its not worth the fight. relatively valuable penditures increase 'ely valuable rent. ${ }^{9}$ also depends on the 2 equilibrium when y prove uniqueness is even larger than ch a game, and we in Figure 1, where has $V>4[(1+x)]$ rows in the figures. tat the symmetrical al equilibrium is

ofit Equation 3, we

ject to competition. ppendix E we prove $V / 4>N$, then $\partial \rho_{e} /$ han $(V-4 N) / V$ or,

$\checkmark$, then equilibrium

ilibrium is static, but the model.

on a thrice continuously

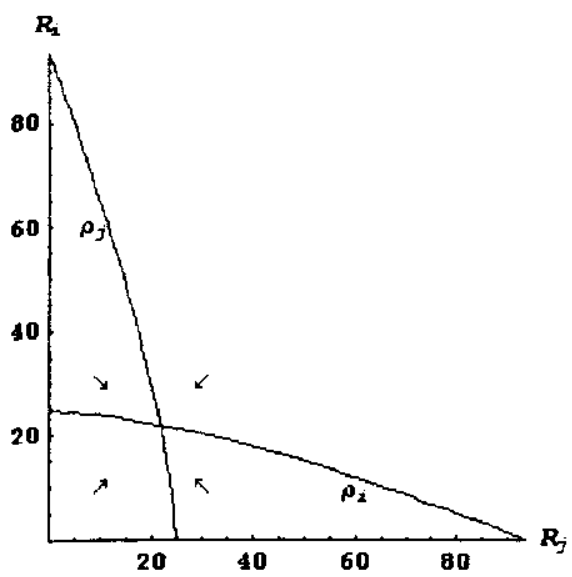

Figure 1A: Case of $V<4 N$ where $V=100 ; N=30 ; \alpha=3 / 4$

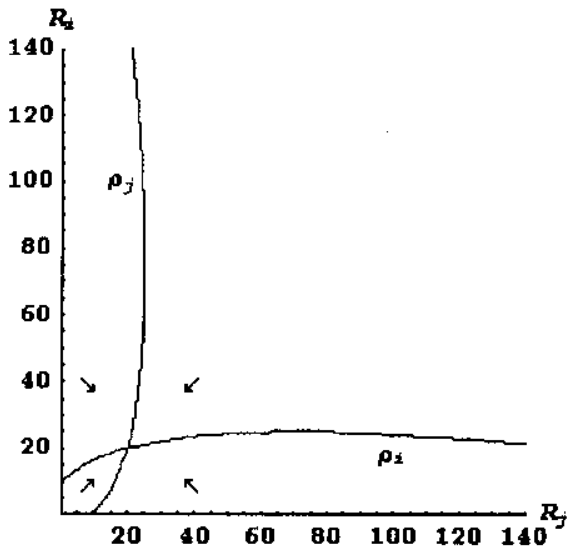

Figure 1C: Case of $V>$ $4[(1+\alpha) / \alpha]^{2} N>4 N$

where $V=100 ; N=1 ; \alpha=1 / 3$

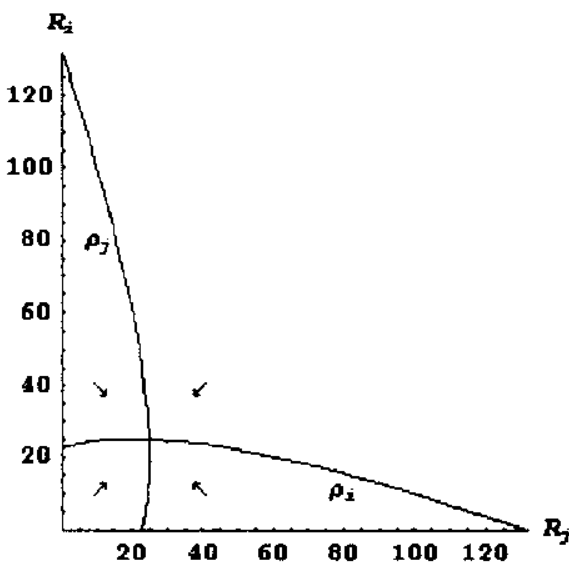

Figure $1 B$ : Case of $4[(1+\alpha) / \alpha]^{2} N$ $>V>4 N$

where $V=100 ; N=12 ; \alpha=2 / 3$

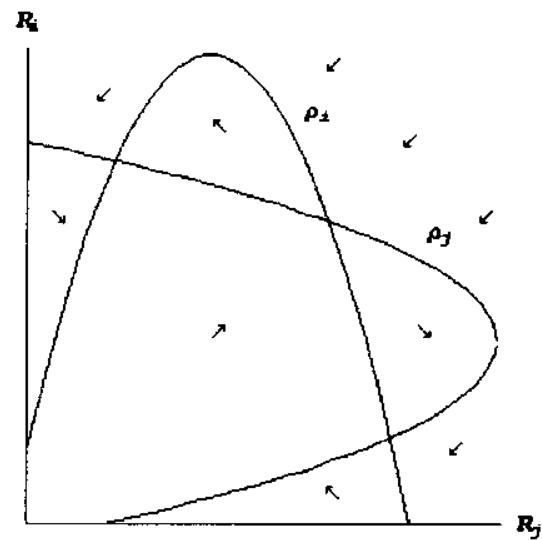

Figure 1D: Possible Case of $V>$ $4[(1+\alpha) / \alpha]^{2} N>4 N ?$

Unproven Possibility of Multiple Equilibria

Figure 1. The shape of reaction functions, equilibrium, and stability.

lobbying expenditures will fall as competition increases, while if $V$ is sufficiently large relative to $N$, then there is a range where $N$ is sufficiently small that equilibrium lobbying expenditures will rise as competition increases before they begin to fall at higher levels of competition. In Figure $1 \mathrm{~A}, V / 4<N$, and in Figure 1B, $(1-\alpha) V / 4<N$, so the equilibrium would move toward the origin if $\alpha$ increases. In these figures, lobbying expenditures are strategic substitutes in the neighborhood of equilibrium. In Figure $1 \mathrm{C},(1-\alpha) V / 4>N$, where expenditures are strategic complements in the neighborhood of equilibrium, the equilibrium would move away from the origin.

Intuitively, one might expect that as competition increases, so would the equilibrium lobbying expenditures. This view finds support in some previous models that rely on the number of firms or entry conditions to model competition (Posner 1975; Rogerson 1982; Sun and $\mathrm{Ng}$ 1999). Our model, however, predicts that the effect of competition depends on the value of the rent relative to the 
political costs of supplying the rent. Greater competition decreases expenditures if $V \leq 4 N$ and for lower levels of $\alpha$ where $V>4 N$. This result is in line with empirical research in political science, which indicates that firms lobby policymakers on issues with a low $N$, such as requesting a rent that is consistent with the officials' ideology and/or constituency interests or has low visibility, and on issues over which there is little competition (small $\alpha$ ) (Lowi 1969; Browne 1995; Wolpe and Levine 1996). This also reflects the empirical result in economics that campaign contributions are more likely to "buy votes" on narrow issues with concentrated benefits and dispersed costs than on broader issues (Stratmann 1991, 1995). In other words, firms look for issue niches where their rent-seeking activities are unlikely to conflict with other firms' activities, and the granting of the good will not offend other interests (Evans 1991; Hojnacki and Kimball 1998). Finally, this parallels earlier theoretical results that the dissipation rate can decrease as the number of firms increases (e.g., Baye, Kovenock and de Vries 1993). Greater competition causes an increase in spending only when the rent is very valuable compared with the political costs involved.

Next, we consider the effect of competition on expected profits. The envelope theorem is not applicable (Nti 1997). In Appendix $\mathrm{F}$ we show that if $V$ is sufficiently large relative to $N$, then $\partial \Pi_{i}^{e} / \partial \alpha$ is unambiguously negative. Beyond this it becomes difficult to sign $\partial \Pi_{i}^{e} / \partial \alpha$, but numerous graphs of equilibrium profit for many relative values of $V$ and $N$ invariably show the profit to be decreasing in $\alpha$ and strictly convex over $\alpha \in(0,1] .{ }^{11}$

\section{Dissipation When $\sigma=1$}

In the standard model, underdissipation occurs if $\sigma=1$. Baye, Kovenock, and de Vries (1994) showed that if $\sigma=1$, the equilibrium dissipation rate is $V(n-1) / n$, or simply $V / 2$ in the two-player case. In contrast, our model predicts less than $50 \%$ dissipation almost everywhere on the best reply function. To see this, first note that the two firms' combined lobbying expenditures sum to

$$
\rho_{T}=2 \rho_{e}=\frac{\sqrt{4(1+\alpha) N V+\alpha^{2} V^{2}}+\alpha V-2(1+\alpha) N}{(1+\alpha)^{2}},
$$

so the derivative of the firms' total lobbying expenditures with respect to $N$ is

$$
\frac{\partial \rho_{T}}{\partial N}=\frac{2(1+\alpha) V\left(\sqrt{4(1+\alpha) N V+\alpha^{2} V^{2}}\right)^{-1}-2(1+\alpha)}{(1+\alpha)^{2}} .
$$

The second derivative is obviously negative because $N$ appears only in the inverted radical in the numerator of Equation 8, so the derivative is strictly concave in $N$. Then $\partial \rho_{T} / \partial N=0$ (so $\rho$ reaches a maximum) when the numerator equals zero. At this point, $N=(1-\alpha) V / 4 \geq 0 .{ }^{12}$

Given the preceding, we prove that total lobbying expenditures are less than $V / 2$ almost everywhere.

THEOREM 2: For any $N$ and $\alpha$, the firms' total lobbying expenditures, $\rho_{T}=2 \rho_{e}$, are less than $V / 2$ everywhere except at the point where $N=(1-\alpha) V / 4$.

\footnotetext{
"Nti (1997) completely derived comparative statics for a game similar to ours, but he was able to do so because he did not have nonmonotonicities in the derivatives of expenditures with respect to the parameters.

${ }^{12}$ To see this, set the numerator of Equation 8 equal to zero and simplify to get $V\left[4(1+\alpha) N V+\alpha^{2} V^{2}\right]^{-(1 / 2)}=1$. From this, it follows that $V=\left[4(1+x) N V+x^{2} V^{2}\right]^{1 / 2} \Rightarrow V^{2}=4(1+x) N V+x^{2} V^{2} \Rightarrow N=(1-x) V / 4 \geq 0$.
}

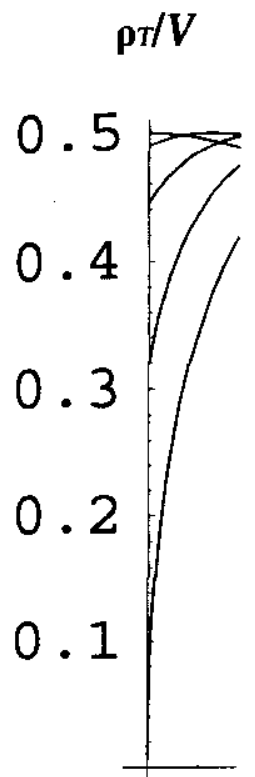

Note: $\rho_{T} / V$ is thi

Figure 2. Dissipation

Proof: See A

Thus, firms $w$ so for two reasons. spend very much $\mathbf{r}$ probability of firms approaching zero : under various degr $N \in(0, V)$ for selec $\alpha=1$ and $N \rightarrow 0$; a increases in $N$. For any value of $\alpha$, the

These results seeking outlays as so must lobbying. lobbying efforts be the property that $\mathrm{lc}$ lobbying other legi against the policy.

We derived $c$

\footnotetext{
${ }^{13}$ In other words, becal
} spend as much as in 
if $V \leq 4 N$ and for tical science, which sting a rent that is sility, and on issues and Levine 1996). are more likely to 1 on broader issues It-seeking activities ill not offend other - theoretical results Kovenock and de nt is very valuable ope theorem is not to $N$, then $\partial \Pi_{i}^{e} / \partial \alpha$ umerous graphs of to be decreasing in

ad de Vries (1994) ? in the two-player $\approx$ on the best reply es sum to

rted radical in the $=0$ (so $\rho$ reaches 12 than $V / 2$ almost , are less than $V / 2$

recause he did not have $\left.{ }^{2}\right]^{-(1 / 2)}=1$. From this,

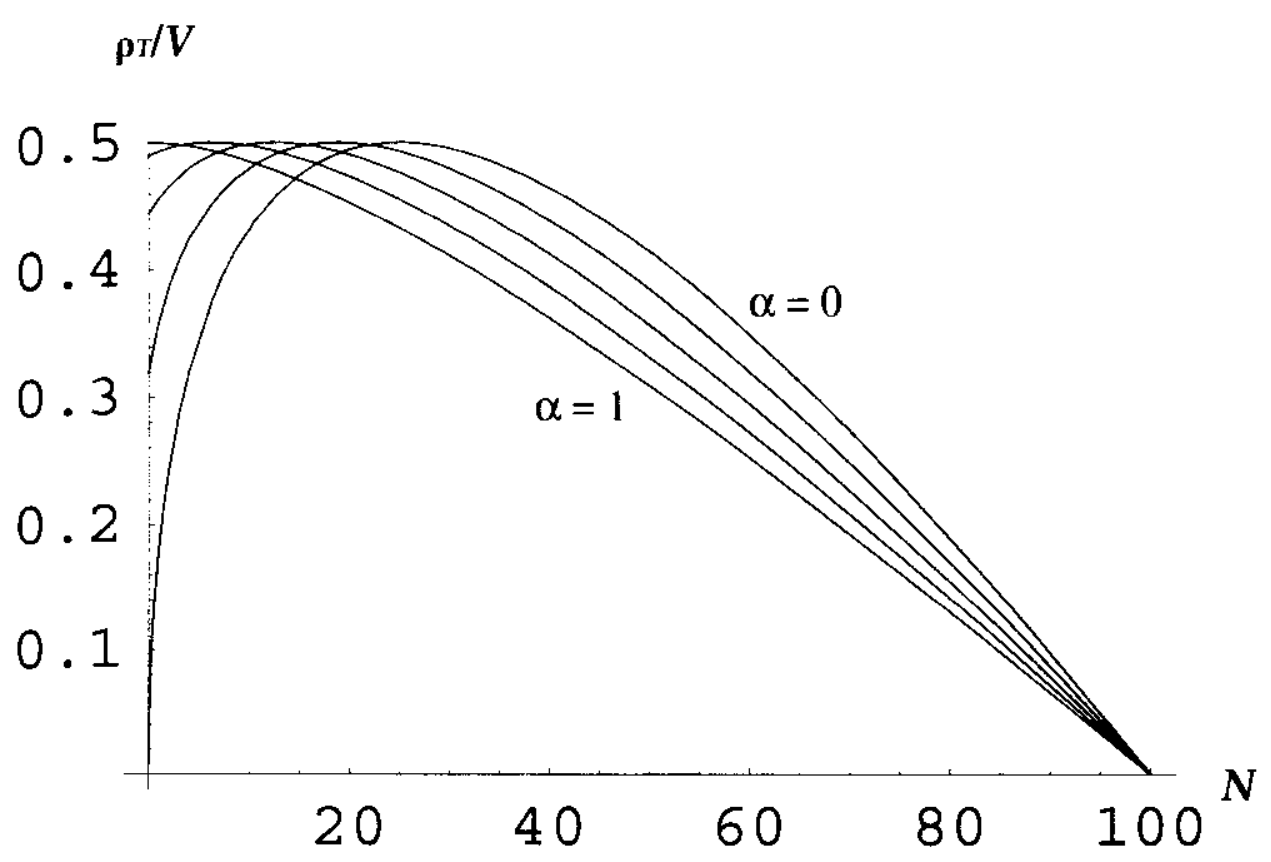

Note: $\rho_{T} / V$ is the dissipation rate, and $V=100$. Each curve corresponds to a different $\alpha$.

Figure 2. Dissipation rate as a function of policymakers' costs for various values of $\alpha$.

Proof: See Appendix G.

Thus, firms will spend less than in the standard model except at a point of measure zero. ${ }^{13}$ This is so for two reasons. First, for $N<(1-x) V / 4$, political costs are low enough that firms do not have to spend very much relative to the size of the rent. For $N>(1-\alpha) V / 4$, rising political costs lower the probability of firms being able to gain the rent, thereby causing equilibrium rent dissipation to decrease, approaching zero as $N \rightarrow V$. Figure 2 demonstrates the effects of policymaker costs on dissipation under various degrees of competition. Here, $V=100$ and the dissipation rate (or $\rho_{T} / V$ ) is plotted over $N \in(0, V)$ for selected values of $\alpha$. Recall that the standard game is a special case of our model in which $x=1$ and $N \rightarrow 0$; at this point in Figure 2 the dissipation rate is $50 \%$ and decreases monotonically with increases in $N$. For other values of $\alpha$, the dissipation rate is maximized at $50 \%$ at $N=(1-\alpha) V / 4$. For any value of $\alpha$, the dissipation rate is less than $30 \%$ for about half the range of $N \in(0,100)$.

These results are highly intuitive. Policymakers with low costs require relatively small rentseeking outlays as long as the level of competition is low. As policymakers' costs increase, however, so must lobbying. But for sufficiently high policymaker costs, where $N \geq(1-\alpha) V / 4$, continued lobbying efforts become less profitable. Firms' expenditures decline to zero as $N \rightarrow V$. This reflects the property that lobbying a legislator with parliamentary rights over a policy area is worth more than lobbying other legislators. Similarly, agents are less likely to lobby policymakers with a predisposition against the policy.

We derived our preceding results under the assumption that benefits are equal for both firms.

\footnotetext{
${ }^{13}$ In other words, because $N$ and $V$ are continuous real variables, the a priori probability of $N$ being equal to $(1-x) V / 4$, so firms spend as much as in the standard model, is zero.
} 
Unequal benefits would result in unequal profits and expenditures (the firm with the higher valuation would spend more). However, this would not damage our qualitative results as long as we change Assumption 1 to

Assumption 2: $\min \left\{V_{1}, V_{2}\right\}>N$.

\section{Cases of $\sigma>1$ and $\sigma>2$ : Increasing Returns}

As discussed in Section 2, the case of $\sigma>n /(n-1)$ drew attention in the literature following Tullock (1980) because total spending exceeded potential rents. Baye, Kovenock, and de Vries (1999) suggested that spending zero dominates such an equilibrium, and showed that the standard game has a pure-strategy equilibrium if and only if $\sigma>n /(n-1)$. However, overdissipation occurs in mixed strategies roughly half the time (Baye, Kovenock, and de Vries 1999). To consider increasing returns in the model incorporating politics, we generalize the profit maximization problem to

$$
\max _{R_{i}} \prod_{i}=\left[\frac{R_{i}^{\sigma}}{R_{i}^{\sigma}+\alpha R_{j}^{\sigma}+N}\right] V-R_{i}, \quad \text { where } \sigma>1 .
$$

As in previous literature, we restrict attention to cases where $\sigma$ is an integer. The first-order condition is

$$
\frac{\partial \prod_{i}}{\partial R_{i}}=\left[\frac{\sigma R_{i}^{\sigma-1}}{R_{i}^{\sigma}+\alpha R_{j}^{\sigma}+N}\right] V-\left[\frac{\sigma R_{i}^{2 \sigma-1}}{\left(R_{i}^{\sigma}+\alpha R_{j}^{\sigma}+N\right)^{2}}\right] V-1=\left[\frac{\sigma\left(\alpha R_{j}^{\sigma}+N\right) R_{i}^{\sigma-1}}{\left(R_{i}^{\sigma}+\alpha R_{j}^{\sigma}+N\right)^{2}}\right] V-1=0 .
$$

To determine the reaction function, we might rearrange the first-order condition to obtain $R_{i}$ as a function of $R_{j}$. This results, however, in a complicated quartic function. Instead, we prove in Appendix $\mathrm{H}$ that the first-order condition implicitly defines $R_{i}$ as a function of $R_{j}$, except possibly at a point of measure zero. ${ }^{14}$ This implicit function can conceptually be rearranged to an explicit form of Firm $i$ 's reaction function. A symmetrical equilibrium would require that

$$
\begin{aligned}
& {\left[\frac{\sigma\left(\alpha R_{j}^{\sigma}+N\right) R_{i}^{\sigma-1}}{\left(R_{i}^{\sigma}+\alpha R_{j}^{\sigma}+N\right)^{2}}\right] V-1=0} \\
& \text { and } R_{1}=R_{2}>0 \text { with } \Pi_{1}=\Pi_{2} \geq 0
\end{aligned}
$$

so the firms are maximizing profit (by Eqn. 11), where expenditures are positive and profits are nonnegative (by Conditions 12). Consider a case where $\sigma=2, n=2, V=100, N=25, \alpha=1 / 3$, and $R_{1}=$ $R_{2}$. Figure 3 plots the graph of Equation 11 between $R_{1}=R_{2}=0$ and $R_{1}=R_{2}=100=V .{ }^{15}$ There is only one positive $R_{i}$ where the first-order condition is satisfied and $R_{1}=R_{2}>0$. Closer inspection reveals that the equilibrium $R_{i}$ falls between 38.42 and $38.43 .{ }^{16}$ At these values, the expected profits are 27.50 and 27.49. Thus, Equation 11 and Conditions 12 are satisfied, and we have found a symmetrical Nash equilibrium in pure strategies. In this equilibrium the rent is approximately $76.85 \%$ dissipated.

We perform the same operations for a case where $\sigma=3, n=2, V=100, N=25, \alpha=1 / 4$, and $R_{1}=$

\footnotetext{
14 The Implicit Function Theorem gives sufficient, but not necessary, conditions for a function to exist. Failure of the conditions at a single point does not mean that a function cannot exist at that point (Chiang 1984). Moreover, because the theorem fails only at a point of measure zero, the function certainly exists around neighborhoods at all other points.

${ }^{15}$ Recall that firms would certainly spend no more than $R_{1}=R_{2}=V$.

${ }^{16}$ At $R_{i}=38.42, \partial \Pi_{j} / \partial R_{i}=0.00008$, while at $R_{i}=38.43, \partial \Pi_{i} / \partial R_{i}=-0.00019$, so we have found the neighborhood of a maximum.
}

$\partial \Pi_{i} / \partial R_{i}$

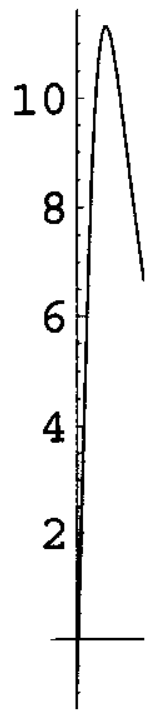

Note: $\partial \Pi_{i} / \partial R_{i}$ is $t$ equilibrium

Figure 3. Determining

$R_{2}$. Figure 4 graphs with corresponding with policymaker $\mathbf{c}$ Nash equilibrium is

\section{Conclusion}

The approach policymaker costs : greater verisimilitu how firms allocate

Intuitively, in discussed regardin: Incorporating polic underlying success different conclusior our Theorem 1 indi

\footnotetext{
17 Again, by "standard r of rent seeking.
} 
with the higher valuation its as long as we change

1 the literature following ock, and de Vries (1999) it the standard game has ipation occurs in mixed nsider increasing returns roblem to

le first-order condition is $\left.\frac{i-1}{N)^{2}}\right] V-1=0$.

adition to obtain $R_{i}$ as Instead, we prove in of $R_{j}$, except possibly iged to an explicit form

ositive and profits are $=25, \alpha=1 / 3$, and $R_{1}=$ $00=V \cdot{ }^{15}$ There is only ser inspection reveals ected profits are 27.50 id a symmetrical Nash $85 \%$ dissipated.

$=25, \alpha=1 / 4$, and $R_{1}=$

st. Failure of the conditions : because the theorem fails wints.

sund the neighborhood of

\section{$\partial \Pi_{i} / \partial R_{i}$}

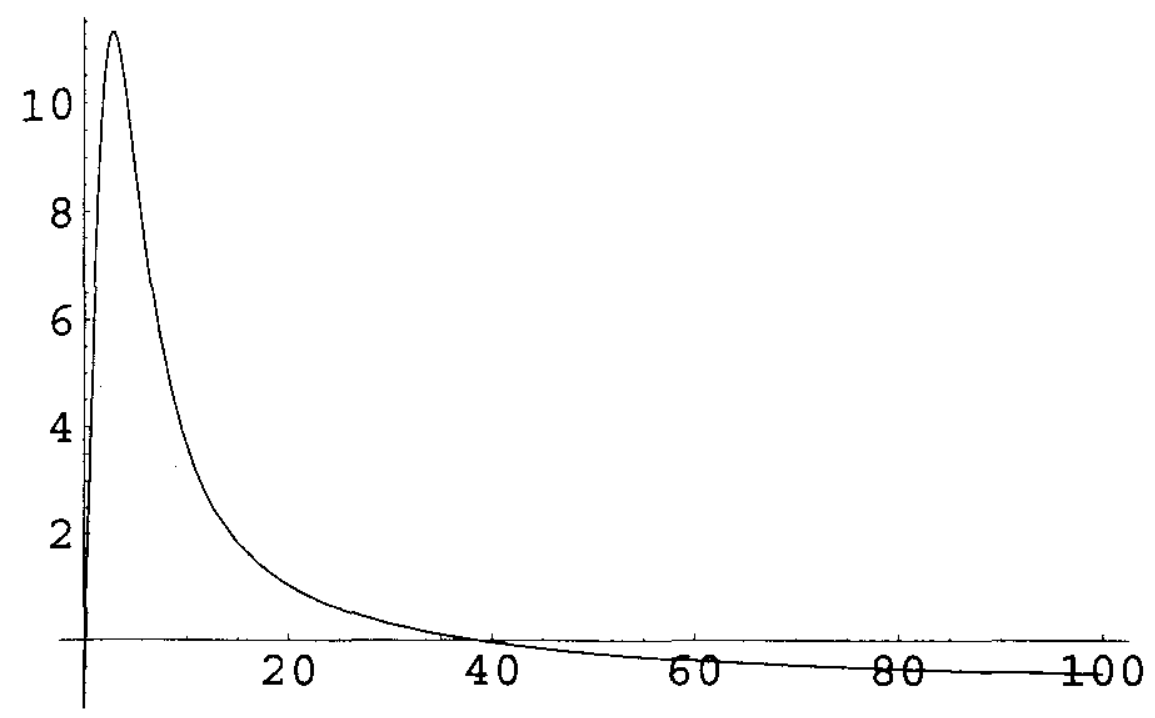

$\boldsymbol{R}_{\boldsymbol{i}}$

Note: $\mathrm{\partial} \Pi_{i} / \partial R_{i}$ is the first order condition, which is the implicit reaction function. The symmetric equilibrium is found by setting $R_{1}=R_{2}$.

Figure 3. Determining a symmetric equilibrium when $\sigma=2, n=2, V=100, N=25$, and $\alpha=1 / 3$.

$R_{2}$. Figure 4 graphs the first-order condition. Here, the equilibrium $R_{i}$ falls between 48.02 and 48.03 , with corresponding profits of 31.97 and 31.96 , and the dissipation rate is approximately $96.05 \%$. Thus, with policymaker costs and political competition incorporated into the standard game, a symmetrical Nash equilibrium in pure strategies exists with underdissipation of rents, even for $\sigma>n /(n-1)$.

\section{Conclusion}

The approach outlined here emphasizes the politics involved in rent-seeking games. Adding policymaker costs and offering an alternative conceptualization of competition between firms provide greater verisimilitude to the political process and a more reasonable approximation to the question of how firms allocate resources to rent seeking.

Intuitively, incorporating politics serves to generalize the standard rent-seeking model. As we discussed regarding Equations 1 and 2, the standard model is a special case of our model. ${ }^{17}$ Incorporating policymaker costs $(N)$ and political competition $(\alpha)$ fundamentally alters the game's underlying success probabilities, which changes the way firms behave in the model. This leads to very different conclusions regarding lobbying behavior and the social costs of rent seeking. For example, our Theorem 1 indicates that firms will avoid political competition in many cases, rather than spend

\footnotetext{
17 Again, by "standard model" we refer to the class of games that follow the approach based on Tullock's (1980) lottery model of rent seeking.
} 
$\partial \Pi_{i} / \partial R_{i}$

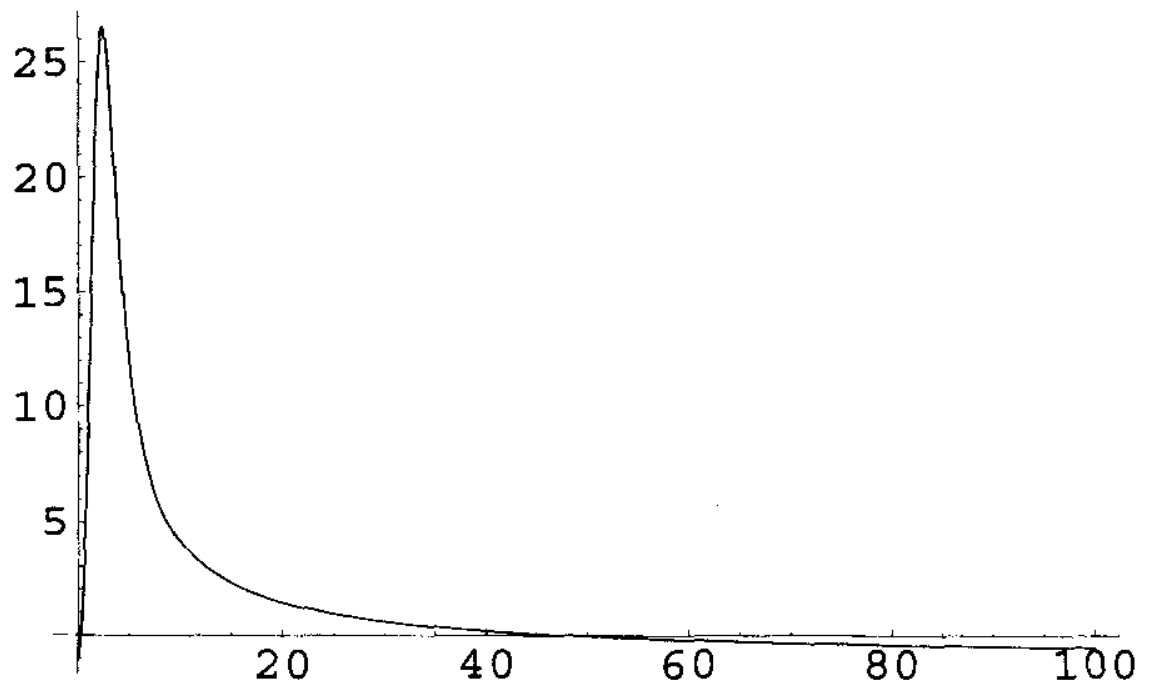

LEMAMA Al. The $R_{i}$ an

Proof. By Assumptic 0 , so the $R_{j}$ intercept is pos

We next establish Firm i's

LeMMA A2. Firm $i$ 's

Proof. Expected pro

Note: $\partial \prod_{i} / \partial R_{i}$ is the first order condition, which is the implicit reaction function. The symmetric equilibrium is found by setting $R_{1}=R_{2}$.

Figure 4. Determining a symmetric equilibrium when $\sigma=3, n=2, V=100, N=25$, and $\alpha=1 / 4$.

more under greater competition. In fact, our model finds that dissipation rates are generally lower than the standard model suggests (Theorem 2), even under increasing returns to rent-seeking expenditures as shown in section 7. Much of what has followed Tullock's seminal contribution consists of mathematically elegant extensions that generate politically complicated results. The model we advance is much simpler. In its results, we see that the political context helps to determine the strategies that firms will use, as well as the likely outcomes of rent-seeking expenditures.

In short, as the policy that embodies the rent is more costly for policymakers to pass, ceteris paribus, rent seekers are less likely to win the rent and will be less interested in lobbying for it. Rent seekers will similarly avoid lobbying where there are intense counteracting efforts from other interestsexpected profits are higher where political competition is lower. In addition, political costs and competition will dissuade rent seekers from spending more to win a prize than the value of the prize itself.

\section{Appendix A: The Best Reply Functions}

Rearranging Equation 4 yields the profit-maximizing level of $R_{i}$ as a function of $R_{j}$ and exogenous variables:

$$
R_{i}=\sqrt{\left(x R_{j}+N\right) V}-x R_{j}-N .
$$

From Equation $\mathrm{A} 1$, note that (1) $R_{i}>0$ if $R_{j}$ is sufficiently low that it pays Firm $i$ to lobby; (2) $R_{i}=0$ at a sufficiently high $R_{j}$; and (3) $R_{i}<0$ for even higher $R_{j}$, which is not feasible because $R_{i} \geq 0$. We restrict analysis to $R_{i}, R_{j} \geq 0$. We next establish that the $R_{i}$ and $R_{j}$ intercepts of Equation $\mathrm{Al}$ are positive. Then, because Equation $\mathrm{Al}$ is obviously continuous, we know that the best reply function passes through the first quadrant in $R_{i}-R_{j}$ space. It follows that for $N \in(0, \infty)$, there are points of Equation $\mathrm{Al}$ at which $R_{i}$ and $R_{j}$ are both positive. From Equation $\mathrm{A} 1$, the $R_{i}$ and $R_{j}$ intercepts are 


$$
\begin{aligned}
\left.R_{i}\right|_{R_{j}-11} & =\sqrt{N V}-N \\
\text { and }\left.\quad R_{f}\right|_{R_{1}-31} & =\frac{V-N}{\boldsymbol{x}} .
\end{aligned}
$$

LemmA Al. The $R_{i}$ and $R_{j}$ intercepts of Equation Al are positive. Furthermore, the $R_{i}$ intercept is less than the $R_{j}$ intercept.

Proof. By Assumption $1, V>N$, hence $\sqrt{N V}-N>0$, so the $R_{j}$ intercept is positive. $V-N>0$ and $x>0 \Rightarrow(V-N) / \alpha>$ 0 , so the $R_{j}$ intercept is positive. Because $\alpha \in(0,1)$, we have

$$
\frac{V-N}{\boldsymbol{x}}>\frac{\sqrt{N V}-N}{\boldsymbol{x}} \geq \sqrt{N V}-N . \quad Q E D .
$$

We next establish Firm $i$ 's willingness to invest in lobbying according to Equation 5 in the paper.

Lemma A2. Firm $i$ 's profit is nonnegative on Equation $\mathrm{A} 1$ for $R_{i} \in[0, \sqrt{N V}-N]$.

PROOF. Expected profit is

$$
\prod_{i}=\left[\frac{R_{i}}{R_{i}+x R_{j}+N}\right] V \cdots R_{i}
$$

Obviously, if $R_{i}=0$, then $\prod_{i}=0$. Next, consider $R_{i} \in(0, \sqrt{N V}-N)$. Rearranging Equation A4, we see that profit is nonnegative if $V-\alpha R_{j}-N \geq R_{i}$, which by Equation $\mathrm{A} 1$ can be expressed as $V-\alpha R_{j}-N \geq R_{i}=\sqrt{\left(\alpha R_{j}+\bar{N}\right) \bar{V}}-\alpha R_{j}-N$. So profit is nonnegative if

$$
V \geq \sqrt{\left(\alpha R_{j}+N\right) V}
$$

We complete the proof by showing that Equation A5 holds on Equation A1. The right side of Equation $\mathrm{A} 5$ increases in $R_{j}$, which reaches a maximum of $(V-N) / \alpha$ in the interval of this lemma. Then, because $\left(V-N_{R}\right) / \alpha \geq R_{j}$,

$$
\sqrt{[\alpha(V-N) / \alpha+N] V}=V \geq \sqrt{\left(\alpha R_{j}+N\right) V} . \quad Q E D .
$$

Defining the set of $R_{i}$ values that satisfy Equation $\mathrm{Al}$ as $\rho_{i}$, we have proven

THEOREM Al. The best reply function of Firm 1 is

$$
\rho_{i}=\left\{\begin{array}{cl}
\sqrt{\left(x R_{j}+N\right) V}-x R_{j}-N & \text { for } 0 \leq R_{j} \leq \frac{(V-N)}{x} \\
0 & \text { for } \frac{(V-N)}{x}<R_{j}
\end{array}\right.
$$

\section{Appendix B: The Shape of the Best Reply Functions}

We show that $\rho_{i}$ is strictly concave over $R_{j} \in[0,(V-N) / \alpha]$, but that its exact shape depends on the relative magnitudes of $V$ and $N$. Two lemmas prove these conjectures and will be useful tater.

LEMMA B1. Fim $i$ 's best reply function is strictly concave over $R_{j} \in[0,(V-N) / \alpha]$.

Proof. The first derivative of $\rho_{i}$ with respect to $R_{j}$ is

$$
\frac{\partial \rho_{i}}{\partial R_{j}}=\frac{\alpha \sqrt{V}}{2 \sqrt{x R_{j}+N}}-\alpha
$$

and the second derivative is therefore

$$
\frac{\partial^{2} \rho_{i}}{\partial \boldsymbol{R}_{j}^{2}}=\frac{-x^{2} \sqrt{V}}{4 \sqrt{\left(\alpha R_{j}+N\right)^{3}}}
$$

which is clearly negative. Therefore, $\rho_{i}$ is strictly concave. $Q E D$.

LEMMA B2. If $V \leq 4 N$, then $\rho_{i}$ is monotonically decreasing over $R_{j} \in[0,(V-N) / \alpha]$. If $V>4 N$, then $\rho_{i}$ has an interior maximum at $R_{j}=(V / 4-N) / \alpha$, which is in the interior of $[0,(V-N) / \alpha]$.

PRCOF. The slope of $\rho_{i}$ is given by $\partial \rho_{i} / \partial R_{j}$. Rearranging Equation $B 1$, we see that 


$$
\frac{\partial \rho_{i}}{\partial R_{j}}>0 \Leftrightarrow R_{j}<\frac{V / 4-N}{\alpha} . \quad \frac{\partial \rho_{i}}{\partial R_{j}}=0 \Leftrightarrow R_{f}=\frac{V / 4-N}{\alpha}, \quad \text { and } \quad \frac{\partial \rho_{t}}{\partial R_{j}}<0 \Leftrightarrow R_{j}>\frac{V / 4-N}{\alpha} .
$$

We are concerned with $\rho_{i}$ over $R_{j} \in[0 .(V-N) / \alpha]$. Now $V / 4-N<V-N$, so $(V / 4-N) / \alpha<(V-N) / \alpha$. Thus, the critical point $R_{j}=(V / 4-N) / \alpha$ is less than $(V-N) / \alpha$. However, if $V$ is small enough that $(V / 4-N) / \alpha \leq 0$, then $R_{j}$ cannot be less than $(V / 4-$ $N) / \alpha$ since $R_{j}$ cannot be negative. It follows that $\partial \rho_{i} / \partial R_{j} \leq 0$ on $R_{j} \in\{0,(V-N) / \alpha]$. Note that $(V / 4-N) / \alpha \leq 0$ implies that $V \leq$ $4 N$. Thus, if $V \leq 4 N$, then $\rho_{i}$ is decreasing and strictly concave in $R_{j}$. However, if $V>4 N$, then there exists an interior maximum for $\rho_{i}$ in $[0,(V-N) / x]$. Because the second derivative is negative by Lemma Bl, $\rho_{i}$ reaches a maximum where $R_{j}=(V / 4-$ $N) / \alpha$. Hence, if $V>4 N$, then $\rho_{i}$ has an interior maximum at $R_{j}=(V / 4-N) / \alpha \in(0,(V-N) / \alpha)$. QED.

\section{Appendix C: Equilibrium}

We must establish the existence of equilibria because games with infinite strategy sets may not have an equilibrium (Morrow 1994). We first note the following: (I) the strategy space $R_{i} \in[0, V]$ for $i=1,2$ are compact and convex; (2) the expected profit function $\Pi_{i}=\left[R_{i} /\left(R_{i}+x R_{j}+N\right)\right] V-R_{i}$ is defined, continuous, and bounded on the strategy sets; and (3) $\Pi_{i}$ is strictly concave in $R_{j}$ because $\partial^{2} \Pi j \partial R_{i}^{2}<0$.

THEOREM Cl. The game has at least one Nash equilibrium.

Proof. The profit function is concave, hence it is also quasiconcave. This, together with points (1) and (2) above, satisfies the conditions for a well-known existence proof for Nash equilibrium (Fudenberg and Tirole 1995). $Q E D$.

Thus, there exists at least one Nash equilibrium. However, it is possible that multiple equilibria exist. We therefore consider uniqueness. To this end, we establish

THEOREM C2. If $V \leq 4 N$, then there is a unique Nash equilibrium for the game. Furthermore, the equilibrium is symmetric, so in equilibrium $\rho_{i}=\rho_{j}$.

Proof. By Theorem 3.4 of Friedman (1990), and given points 1 and 2 above, a unique equilibrium exists as long as the best reply functions are contractions. In our game, the best reply functions, Equation 5 , do not contain $R_{i}$ on the right side. Thus, because the best reply functions are symmetrical, they are contractions if the value of $\left|\partial \rho_{i} / \partial R_{j}\right|$ for Equation 5 is less than one. Suppose $V \leq 4 N$, then, by Lemmas B1 and B2, $\rho_{1}$ is monotonically decreasing and strictly concave. Hence, $\partial \rho_{i} / \partial R_{j} \leq$ 0 and reaches its minimum value at the largest possible value of $R_{j}$, where $R_{j}=(V-N) / \alpha$. Substituting this into Equation 5 , we get

$$
\frac{\partial \rho_{i}}{\partial R_{j}} \geq \frac{\alpha \sqrt{V}}{2 \sqrt{\alpha(V-N) / \alpha+N}}-\alpha=\frac{\alpha \sqrt{V}}{2 \sqrt{V}}-\alpha=\frac{-\alpha}{2}
$$

$|-\alpha / 2| \leq 1 / 2$ because $\alpha \in(0,1]$, so $0 \leq\left|\partial \rho_{i} / \partial R_{j}\right| \leq 1 / 2<1$, and uniqueness is guaranteed for $V \leq 4 N$. Symmetry of the functions implies that the unique equilibrium is where $\rho_{1}=\rho_{2}$. $Q E D$.

Uniqueness is not so easy to show in the case where $V>4 N$ because the best reply function is not necessarily a contraction. As $R_{j}$ approaches 0 from above, $\partial \rho_{i} / \partial R_{j}$ increases, approaching

$$
\frac{\alpha \sqrt{V}}{2 \sqrt{N}}-\alpha>\frac{\alpha \sqrt{4 N}}{2 \sqrt{N}}-\alpha=0
$$

While we know that the derivative is greater than 0 , we have no upper bound for it. Certainly, for some cases the derivative will be less than 1, but this will not hold with generality. Another well-known uniqueness theorem requires the Jacobian of the best reply functions to be negative quasidefinite (e.g., Friedman 1990). However, our best reply functions do not satisfy this condition. On the other hand, we can apply the contraction theorem to special cases where $V>4 N$. We have

THEOREM C3. If $4\left(\frac{1+x}{x}\right)^{2} N>V>4 N$, there is a unique Nash equilibrium for the game. The reaction functions are symmetrical, so in equilibrium $\rho_{i}=\rho_{j}$.

Proof. This is not a vacuous case, because $(1+\alpha) / \alpha>1$. By Theorem 3.4 of Friedman $(1990)$, we must show that the best reply function is a contraction. For the decreasing portion of the best reply function, Theorem $\mathrm{C} 2$ indicates that $\left|\partial \rho_{\delta} / \partial R_{j}\right|<1$. On the increasing portion, $\partial \rho_{i} / \partial R_{j} \geq 0$; and the largest value of $\partial \rho_{i} / \partial R_{j}$ occurs at $R_{j}=0$, where, by Equation $\mathrm{B} 1$,

$$
\frac{\partial \rho_{i}}{\partial R_{j}} \leq \frac{\boldsymbol{x} \sqrt{V}}{2 \sqrt{N}}-\boldsymbol{x}
$$

Suppose $V<4\left(\frac{1+x}{x}\right)^{2} N$, the

Thus, on the upward sloping for this function under the $\mathrm{c}$ $p_{i}=p_{j} \quad Q E D$.

We do not prove uni

\section{Appendix D: Equil}

We determine the opt

Rearranging terms, we get (

From the quadratic equation

where it can be shown that

we get

The sign of the term under $t$ it would yield a negative $\rho_{e}$

\section{Appendix E: Proof}

To analyze the effect respect to $\alpha$. After consideri

$$
\frac{\partial \rho_{e}}{\partial \alpha}=\underline{I}
$$

In the following, we concen follows, that $\alpha \in(0,1]$. Defi

LeMma E1. If $\alpha=1$,

Proof. Suppose $\alpha=$

$$
4 N \sqrt{V^{2}+8}
$$

Because the denominator of

Lemma E2. As $\alpha \rightarrow 0^{+}$, a negative limit if and only

Proof. To prove state intermediate result that $\Omega=$ 
Suppose $V<4\left(\frac{1+x}{2}\right)^{2} N$, then

$$
\frac{\partial \rho_{i}}{\partial R_{j}} \leq \frac{x \sqrt{V}}{2 \sqrt{N}}-x<\frac{x \sqrt{4\left(\frac{1-x}{x}\right)^{2} N}}{2 \sqrt{N}}-x=\frac{2(1+x) \sqrt{N}}{2 \sqrt{N}}-x=1 .
$$

Thus, on the upward sloping portion of $p_{i}, 0 \leq \partial \rho_{d} / \partial R_{j}<1$, so the best reply function is a contraction. Therefore, $\left|\partial \rho_{i} / \partial R_{j}\right|<1$ for this function under the condition of this theorem, so there is a unique equilibrium. Symmetry of best reply functions implies $\rho_{i}=\rho_{j} . \quad Q E D$.

We do not prove uniqueness if $V>4\left(\frac{1+x}{x}\right)^{2} N$. but the only stable equilibrium is symmetrical (see text).

\section{Appendix D: Equilibrium Lobbying Expenditures}

not have an equilibrium npact and convex; (2) the $\therefore$ strategy sets; and (3) $\Pi_{i}$

(1) and (2) above, satisfies QED.

libria exist. We therefore

equilibrium is symmetric,

rium exists as long as the $R_{i}$ on the right side. Thus, juation 5 is less than one. icave. Hence. $\partial p_{i} / \partial R_{j} \leq$ ting this into Equation 5 ,

$\leq 4 N$. Symmetry of the

Iction is not necessarily

cases the derivative will the Jacobian of the best ot satisfy this condition.

reaction functions are

must show that the best tes that $\left|\partial \rho_{i} / \partial R_{j}\right|<1$. quation $\mathrm{B} 1$,
We determine the optimal investment at the symmetrical equilibrium. Let $\rho_{i}=\rho_{j}=\rho_{e}$, so $\rho_{e}$ satisfies

$$
\rho_{e}=\sqrt{\left(x \rho_{e}+N\right) V}-x \rho_{e}-N \text { for } \rho_{e} \in[0,(V-N) / x] .
$$

Rearranging terms, we get $(1+x) \rho_{e}+N=\sqrt{\left(x \rho_{e}+N\right) V}$ or

$$
(1+x)^{2} \rho_{e}^{2}+2(1+x) N \rho_{e}+N^{2}=\left(x \rho_{e}+N\right) V=x \rho_{e} V+N V .
$$

From the quadratic equation.

$$
\rho_{e}=\frac{x V-2(1+x) N \pm \sqrt{[2(1+x) N-x V]^{2}-4(1+x)^{2}\left(N^{2}-V N\right)}}{2(1+x)^{2}},
$$

where it can be shown that

$$
[2(1+\alpha) N-\alpha V]^{2}-4(1+\alpha)^{2}\left(N^{2}-V N\right)=\alpha^{2} V^{2}+4(1+\alpha) N V,
$$

we get

$$
\rho_{e}=\frac{x V-2(1+x) N \pm \sqrt{x^{2} V^{2}+4(1+\alpha) N V}}{2(1+x)^{2}} .
$$

The sign of the term under the radical is greater than $\alpha^{2} V^{2}$. so we disregard the solution where the radical is subtracted because it would yield a negative $\rho_{e}$, and we are left with Equation 6 in the text.

\section{Appendix E: Proof of Theorem 1}

To analyze the effect of competition on equilibrium lobbying expenditures, we take the derivative of Equation 6 with respect to $\alpha$. After considerable manipulation, we find that

$$
\frac{\partial \rho_{e}}{\partial \alpha}=\frac{[2(1+\alpha) N+(1-x) V]\left[\sqrt{x^{2} V^{2}+4(1+\alpha) V N}\right]+\alpha(1-\alpha) V^{2}-6(1+\alpha) V N}{2(1+\alpha)^{3} \sqrt{\alpha^{2} V^{2}+4(1+\alpha) V N}} .
$$

In the following, we concentrate on the numerator because the denominator is positive under our assumptions. Recall, in what follows, that $\alpha \in(0,1)$. Define the numerator as $\Omega$.

LemMA E1. If $\alpha=1$, then $\partial \rho_{e} / \partial \alpha<0$.

Proof. Suppose $\alpha=1$, then $\Omega=4 N \sqrt{V^{2}+8 V N}-12 V N$. Because $N<V$ by Assumption 1 ,

$$
4 N \sqrt{V^{2}+8 V N}-12 V N<4 N \sqrt{V^{2}+8 V^{2}}-12 V N=4 N \sqrt{9 V^{2}}-12 V N=12 V N-12 V N=0 .
$$

Because the denominator of $\partial \rho_{e} / \partial \alpha$ is positive, $\partial \rho_{e} / \partial x<0$. QED.

LemMA E2. As $\boldsymbol{x} \rightarrow 0^{+}, \partial \rho_{e} / \partial \boldsymbol{x}$ approaches (1) a positive limit if and only if $V / 4>N$; (2) zero if and only if $V / 4=N$; and (3) a negative limit if and only if $V / 4<N$.

PROOF. To prove statement 1 of Lemma E2, we show that $\Omega>0 \Leftrightarrow V / 4>N$. In doing this, we prove statement 2 by an intermediate result that $\Omega=0 \Leftrightarrow V / 4=N$. Suppose $\alpha \rightarrow 0^{+}$, then $\Omega$ approaches $[V+2 N](\sqrt{4} V N]-6 V N$, and

$$
[V+2 N][\sqrt{4 V N}]-6 V N>0 \Leftrightarrow[V+2 N][\sqrt{4 V N}]>6 V N .
$$


Divide both sides of the inequality by $V+2 N>0$ to see that the latter holds if and only if

$$
\begin{aligned}
\sqrt{4 V N}>\frac{6 V N}{V+2 N} & \Leftrightarrow 4 V N>\frac{36 V^{2} N^{2}}{(V+2 N)^{2}}=\frac{36 V^{2} N^{2}}{V^{2}+4 V N+4 N^{2}} \\
& \Leftrightarrow 4 V^{3} N+16 V^{2} N^{2}+16 V N^{3}>36 V^{2} N^{2} .
\end{aligned}
$$

Divide through the last inequality by $4 V N$ and rearrange terms to get

$$
V^{2}+4 V N+4 N^{2}>9 V N \Leftrightarrow V^{2}-5 V N+4 N^{2}>0 .
$$

The last quadratic equation is strictly convex, so the solutions to the inequality for $N$ lie outside the solutions of the quadratic equality. The solutions are $V=N$ and $V / 4=N$. Because $V>N$ by Assumption 1, we have proved statement 2 of the lemma: $\partial \rho_{d} / \partial x=0$ if and only if $V / 4=N$. Continuing the proof of statement 1, either $V<N$ or $V / 4>N$. Again, the former is contrary to Assumption 1 , so $\partial \rho_{e} / \partial \alpha>0$ if and only if $V / 4>N$. Similar reasoning proves that, because $V>N$ by assumption, $\partial \rho_{e} / \partial \alpha<0$ if and only if $V / 4<N . \quad Q E D$.

Lemma $E 2$ states that $\partial \rho_{e} / \partial \alpha$ approaches zero if $V / 4=N$, but it will not equal zero because $\alpha>0$.

LEMMA E3. $\partial \rho_{e} / \partial \alpha=0$ if and only if $\alpha=(V-4 N) / V \Leftrightarrow N=(1-x) V / 4$.

Proof. Because $N=(1-x) V / 4 \Leftrightarrow 4 N / V=1-\alpha<1$, such an $\alpha$ exists if and only if $V>4 N$. We show that the only solution for $\Omega=0$ under our assumptions occurs where $N=(1-\alpha) V / N \Leftrightarrow \alpha=(V-4 N) / N$. Thus,

$$
\begin{aligned}
& {[(1-\alpha) V+2(1+\alpha) N]\left[\sqrt{\alpha^{2} V^{2}+4(1+\alpha) V N}\right]+\alpha(1-\alpha) V^{2}-6(1+\alpha) V N=0} \\
& \Leftrightarrow[(1-\alpha) V+2(1+\alpha) N]\left[\sqrt{\alpha^{2} V^{2}+4(1+\alpha) V N}\right]=-\alpha(1-\alpha) V^{2}+6(1+\alpha) V N
\end{aligned}
$$

Squaring both sides of the last equation and expanding the terms yieids

$$
\begin{aligned}
& \alpha^{2}(1-\alpha)^{2} V^{4}+4 \alpha^{2}(1+\alpha)(1-\alpha) V^{3} N+4 \alpha^{2}(1+\alpha)^{2} V^{2} N^{2}+4(1+\alpha)(1-\alpha)^{2} V^{3} N \\
& \quad+16(1+\alpha)^{2}(1-\alpha) V^{2} N^{2}+16(1+\alpha)^{3} V N^{3} \\
& =\alpha^{2}(1-\alpha)^{2} V^{4}-12 \alpha(1+\alpha)(1-\alpha) V^{3} N+36(1+\alpha)^{2} V^{2} N^{2} .
\end{aligned}
$$

Subtracting $\alpha^{2}(1-\alpha)^{2} V^{4}$ from both sides of the equality, dividing by $(1+\alpha) V N$, and then subtracting the right side from both sides and simplifying, we get

$$
(1-\alpha) V^{2}+(\alpha-5) N V+4 N^{2}=0 .
$$

Solving the quadratic equation for $N$, we find that $N=(1-\alpha) V / 4$ or $N=V$. The latter contradicts Assumption 1 , so $N=$ $(1-x) V / 4 . \quad Q E D$.

We now proceed to the proof of

THEOREM 1. (1) If $V / 4 \leq N$, then $\partial \rho_{d} / \partial \alpha<0$ at all levels of $\alpha \in(0,1]$. (2) If $V / 4>N$, then $\partial \rho_{d} / \partial \alpha$ is greater than, equal to, or less than 0 as $\alpha$ is less than, equal to, or greater than $(V-4 N) / V$ or, equivalently, as $(1-\alpha) V / 4$ is greater than, equal to, or less than $N$.

PROOF. (1) Suppose $V / 4 \leq N$. By Lemma $E 1, \partial \rho_{e} /\left.\partial \alpha\right|_{\alpha=1}<0$; and by Lemma E2, $V / 4 \leq N \Rightarrow \lim _{\alpha \rightarrow 0^{+}} \partial \rho_{e} / \partial \alpha \leq 0$. By Lemma E3, $\partial \rho_{e} / \partial \alpha=0 \Leftrightarrow \alpha=(V-4 N) / V \Leftrightarrow N=(1-\alpha) V / 4$. But by the assumption of part 1 of Theorem $1, N \geq V / 4>(1-\alpha) V /$ 4, so $\partial \rho_{e} d \partial \alpha \neq 0$ in the interior of $\alpha \in(0,1]$ if $V / 4 \leq N$. Therefore, if $V / 4 \leq N$, the derivative is never so high as 0 . The derivative is obviously continuous, so if $V / 4 \leq N$, then $\partial \rho_{e} / \partial \alpha<0 \forall \alpha \in(0,1]$. (2) Suppose $V / 4>N$. By Lemma $E 1, \partial \rho_{e} /\left.\partial \alpha\right|_{\infty=1}<0$, and by Lemma E2, $V / 4>N \Rightarrow \lim _{\alpha \rightarrow 0^{+}} \partial \rho_{e} / \partial \alpha>0$. If $V / 4>N$, there exists an $\alpha \in(0,1]$ such that $V / 4>(1-\alpha) V / 4>N$ by the continuity of $\alpha$. Hence, if $V / 4>N$, then $\partial \rho / \partial \alpha$ is greater than, equal to, or less than 0 as $\alpha$ is less than, equal to, or greater than $(V-4 N) / N$, or equivalently, as $(1-\alpha) V / 4$ is greater than, equal to, or less than $N$. $Q E D$.

\section{Appendix F: The Effect of Increasing Competition on Profit}

Denoting $\rho_{e}(V, N, \alpha)$ as $\rho_{e}(\alpha)$, the derivative of Equation 7 with respect to $\alpha$ is

$$
\frac{\partial \prod_{i}^{e}}{\partial \alpha}=\rho_{e}^{\prime}(\alpha)\left[\left(\frac{N}{\left[\rho_{e}(\alpha)+\alpha \rho_{e}(\alpha)+N\right]^{2}}\right) V-1\right]+\frac{-\left[\rho_{e}(\alpha)\right]^{2} V}{\left[\rho_{e}(\alpha)+x \rho_{e}(\alpha)+N\right]^{2}}
$$


The second term is obviously negative. Because the tirst-order condition (Eqn. 4 ) holds for any $R_{i}$ and $R_{j}$, including $R_{i}=R_{j}=$ $p_{e}(x)$. and because $x_{p}(x)>0$, we can sign the term in braces as

$$
\left[\frac{N}{\left(\rho_{e}(x)+x \rho_{e}(x)+N\right)^{2}}\right] V-1<\left[\frac{x \rho(x)+N}{\left(\rho_{e}(x)+x \rho_{e}(x)+N\right)^{2}}\right] V-1=0 .
$$

Then the first temn is positive. zero, or negative as $p_{c}^{\prime}(x)$ is negative, zero, or positive. Thus, if $l$ is sufficiently large relative to $N$, then $\partial \mathrm{Il}^{r} / \partial x$ is unambiguously negative, but generally the sign will depend on the values of the parameter.

Je the solutions of the quadratic oved statement 2 of the lemma: . Again, the former is contrary to $N$ by assumption, $\partial \rho_{e} / \partial \alpha<0$ if

ause $x>0$

$'>4 N$. We show that the only hus,

$V N=0$

$(1+x) V N$

$-x)^{2} V^{3} N$

acting the right side from both

radicts Assumption 1, so $N=$

$\exists \rho_{e} / \partial \alpha$ is greater than, equal to, $x) V / 4$ is greater than, equal to,

$N \Rightarrow \lim _{\mathrm{x} \rightarrow 0^{+}} \partial \rho_{\mathrm{e}} / \partial \alpha \leq 0$. By leorem $1, N \geq V / 4>(1-\alpha) V /$ rer so high as 0 . The derivative :mma $\mathrm{E} 1, \partial \mathrm{p}_{e} /\left.\partial \alpha\right|_{x=1}<0$, and $V / 4>(1-x) V / 4>N$ by the ithan, equal to, or greater than

\section{Appendix G: Proof of Theorem 2}

Proxf. Let $x \in(0,1]$ and, by Assumption $I$ and nonnegative political costs, $N \in(0, V)$. Recall that $\rho_{T}$ is maximized at the single point where $N=(1-x) V / 4$. Therefore.

$$
\begin{aligned}
\rho_{t}=2 \rho_{e}= & \frac{\sqrt{4(1+x) N V+x^{2} V^{2}}+x V-2(1+x) N}{(1+x)^{2}} \\
& \leq \frac{\sqrt{(4 / 4)(1+x)(1-x)^{2}+x^{2} V^{2}}+x V-(2 / 4)(1+x)(1-x) V}{(1+x)^{2}} \\
= & \frac{\sqrt{V^{2}}+x V-(1+x)(1-x) V / 2}{(1+x)^{2}}=\frac{(1+x) V-(1+x)(1-x) V / 2}{(1+x)^{2}}=\frac{V}{2} .
\end{aligned}
$$

Because the first derivative is strictly concave, the equality holds only at the point where $N=(1-x) V / 4 ;$ elsewhere $\rho_{T}<V / 2$. Therefore. total lobbying expenditures are less than one half of the value of benefits almost everywhere. $Q E D$.

\section{Appendix H: The Implicit Reaction Function}

We prove that the first-order condition is an implicit function $R_{i}=R_{i}\left(R_{j}\right)$, except possibly at a point of measure zero using the Implicit Function Theorem. We first establish two lemmas where we define

$$
\Psi\left(R_{i}, R_{j}\right) \doteq\left[\frac{\sigma\left(\alpha R_{j}^{\sigma}+N\right) R_{i}^{\sigma-1}}{\left(R_{i}^{\alpha}+\alpha R_{j}^{\sigma}+N\right)^{2}}\right] V-1 .
$$

LEMMA $H 1$. The derivatives $\partial \Psi / \partial R_{i}$ and $\partial \Psi / \partial R_{j}$ are continuous everywhere.

Proof. We prove the lemma for $\partial \Psi / \partial R_{i}$, then it will hold for $\partial \Psi / \partial R_{j}$. Note that

$$
\frac{\partial \Psi}{\partial R_{i}}=\left[\frac{\sigma(\sigma-1)\left(x R_{j}^{\sigma}+N\right) R_{i}^{\sigma-2}}{\left(R_{i}^{\sigma}+x R_{j}^{\sigma}+N\right)^{2}}\right] V-\left[\frac{2 \sigma^{2}\left(\alpha R_{j}^{\sigma}+N\right) R_{i}^{2 \alpha-2}}{\left(R_{i}^{\sigma}+x R_{j}^{\sigma}+N\right)^{3}}\right] V .
$$

Because $N$ is positive, these terms obviously are continuous everywhere. $Q E D$.

LEMMA H2. If $\Psi\left(R_{i}, R_{j}\right)=0, \partial \Psi / \partial R_{i} \neq 0$ except at a point of measure zero.

ProOF, If $\Psi\left(R_{i}, R_{j}\right)=0$,

$$
\left[\frac{\sigma\left(x R_{j}^{\sigma}+N\right) R_{i}^{\alpha-1}}{\left(R_{i}^{\sigma}+x R_{j}^{\sigma}+N\right)^{2}}\right] V=1
$$

We can rewrite $\partial \Psi / \partial R_{i}$ of Lemma $\mathrm{Hl}$ as

$$
\frac{\partial \Psi}{\partial R_{i}}=(\sigma-1) R_{i}^{-1}-\frac{2 \sigma R_{i}^{\sigma-1}}{\left(R_{i}^{\sigma}+x R_{i}^{\sigma}+N\right)}=\frac{(\sigma-1)\left(x R_{j}^{\sigma}+N\right)-(1+\sigma) R_{i}^{\sigma}}{R_{i}\left(R_{i}^{\sigma}+x R_{j}^{\sigma}+N\right)} .
$$

This derivative is nonzero except at $(\sigma \cdots 1)\left(x R_{j}^{\alpha}+N\right)=(1+\sigma) R_{i}^{\pi}$, a point of measure zero on $R_{i}$. QED.

The existence of this point where $\partial \Psi / \partial R_{i}=0$ does not necessarily mean that the function does not exist at this point. because the Implicit Function Theorem establishes sufficient, not necessary, conditions. It is possible for this condition to fail at a point where a function exists (Chiang 1984).

With these two lemmas, we can prove

THEOREM H1. The first-order condition 10 implicitly defines a function $R_{i}=\Phi\left(R_{j}\right)$, except possibly at a point of measure zero. 
PROOF. In our case, the Implicit Function Theorem states that (1) if $\partial \Psi / \partial R_{i}$ and $\partial \Psi / \partial R_{j}$ are continuous; and (2) if, at the point where $\Psi\left(R_{i}, R_{j}\right)=0, \partial \Psi / \partial R_{i}$ is nonzero, then $\Psi\left(R_{i}, R_{j}\right)$ defines an implicit function in neighborhoods around points where these conditions hold. $Q E D$.

\section{References}

Baye, Michael R., Dan Kovenock, and Casper G. de Vries. 1993. Rigging the lobbying process: An application of the all-pay auction. American Economic Review 83:289-94.

Baye, Michael R., Dan Kovenock, and Casper G. de Vries. 1994. The solution to the Tullock rent-seeking game when $R$ is greater than 2: Mixed-strategy equilibria and mean dissipation rates. Public Choice 81:363-80.

Baye, Michael R., Dan Kovenock, and Casper G. de Vries. 1999. The incidence of overdissipation in rent-seeking contests. Public Choice 99:439-54.

Becker, Gary S. 1983. A theory of competition among pressure groups for political influence. Quarterly Journal of Economics 98:371-400.

Browne, William P. 1995. Cultivating congress. Lawrence, KS; University of Kansas Press.

Che, Yeon-Koo, and Ian Gale. 1997. Rent dissipation when rent seekers are budget constrained. Public Choice 92:109-26.

Chiang, Alpha C. 1984. Fundamental methods of mathematical economics. 3rd edition. New York: McGraw-Hill.

Denzau, Arthur T., and Michael C. Munger. 1986. Legislators and interest groups: How unorganized interests get represented. American Political Science Review 80:89-106.

Dougan, William R., and James M. Snyder. 1993. "Are rents fully dissipated?" Public Choice 77:793-813.

Esteban, Joan, and Debraj Ray. 1999. Conflict and distribution. Journal of Economic Theory 87:379-415.

Evans, Diana M. 1991. Lobbying the committee: Interest groups and the house public works and transportation committee. In Interest group politics, 3rd edition, edited by Allan J. Cigler and Burdet A. Loomis. Washington, DC: CQ Press, pp. 257-76.

Friedman, James W. 1990. Game theory with applications to economics. 2nd edition. New York: Oxford University Press.

Fudenberg, Drew, and Jean Tirole. 1995. Game theory. Cambridge, MA: The MIT Press.

Grier, Kevin B., and Michael C. Munger. 1991. Committee assignments, constituent preferences, and campaign contributions. Economic Inquiry 29:24-43.

Hojnacki, Marie, and David C. Kimball. 1998. Organized interests and the decision of whom to lobby in Congress. American Political Science Review 92:775-90.

Kroszner, Randall S., and Thomas Stratmann. 1998. Interest group competition and the organization of congress: Theory and evidence from financial services political action committees. American Economic Review 88:1163-87.

Lockard, Alan A., and Gordon Tullock. 2001. Efficient rent seeking: Chronicle of an intellectual quagmire. Boston: Kluwer Academic Publishers.

Lowi, Theodore. 1969. The end of liberalism: The second republic of the United States. New York: W.W. Norton.

McCormick, Robert E., and Robert D. Tollison. 1981. Politicians, legislation and the economy: An inquiry into the interestgroup theory of government. Boston: Martinus Nijoff.

Morrow, James D. 1994. Game theory for political scientists. Princeton NJ: Princeton University Press.

Moser, Peter. 2000. The political economy of democratic institutions, The Locke Institute Series. Cheltanham, UK, and Northampton, MA: Edward Elgar.

$\mathrm{Nti}, \mathrm{Kofi}$ O. 1997. Comparative statics of contests and rent-seeking games. International Economic Review 38:43-59.

Peltzman, Sam. 1976. Toward a more general theory of economic regulation. Journal of Law and Economics 19:211-40.

Posner, Richard A. 1975. The social costs of monopoly and regulation. Journal of Political Economy 83:807-27.

Rogerson, William P. 1982. The social costs of monopoly and regulation: A game-theoretic analysis. Bell Journal of Economics 13:391-401.

Spindler, Zane A., and Xavier de Vanssay. 2003. Constitutional design for a rent-seeking society: The voting rule choice revisited. Constitutional Political Economy 14:95-105.

Stigler, George J. 1971. The theory of economic regulation. Bell Journal of Economics and Management Science 2:3-21.

Stratmann. Thomas. 1991. What do campaign contributions buy? Deciphering causal effects of money and votes. Southern Economic Journal 57:606-20.

Stratmann, Thomas. 1995. Campaign contributions and congressional voting: Does the timing of contributions matter? Review of Economics and Statistics 77:127-36.

Sun, Guang-Zhen, and Yew-Kwang Ng. 1999. The effect of number and size of interest groups on social rent dissipation. Public Choice 101:251-65.

Tollison, Robert D. 1997. Rent seeking. In Perspectives on public choice: A handbook, edited by Dennis C. Mueller. Cambridge, UK: Cambridge University Press, pp. 506-25.

Tullock, Gordon. 1980. Efficient rent seeking. In Toward a theory of the rent seeking society, edited by James M. Buchanan. Robert D. Tollison, and Gordon Tullock. College Station, TX: Texas A\&M University Press, pp. 131-76.

Waterson, Michael. 1984. Economic theory of the industry. Cambridge, UK: Cambridge University Press.

Wolpe, Bruce C., and Bertram J. Levine. 1996. Lobbying Congress: How the system works. Washington, DC: CQ Press.

\section{What Dr Determir}

\author{
Nathan S. Balke* as
}

In this paper, wi which expectatio from one in whis distinguish betw: ratio are very $p \epsilon$ information abot stock prices and : stock price move nor does it appe:

JEL Classificati

\section{Introduction}

Before 1981, $r$ principal determinar (1981) found that, ur be consistent with $\mathbf{n}$ hypothesis, argues variables. Several pa Shapiro 1991) challe Shiller, on the groun of the subsequent $\mathrm{l} f$ dividend variability, and Shiller 1987; W

By relaxing th، Campbell (1991) att

* Department of $\mathrm{E}$ Reserve Bank of Dallas, I

+ Department of : mwohar@mail.unomaha.e

The authors would comments on a previous s reflect the views of the $\mathrm{Ft}$ Received March $2 \mathrm{C}$ ${ }^{1}$ Cochrane (1991, 1992), explained by time-varyis 1998], and Bulkley and I On the existence of bub 